\title{
Experiment on Track-keeping Performance using Free Running Model Ship
}

\author{
Nam-Kyun $\mathrm{Im}^{* \dagger} \cdot$ Van-Luong Tran ${ }^{* *}$ \\ *, ** Division of Maritime Transportation System, Mokpo National Maritime University, Mokpo, 571-2, Korea \\ 모형 선박을 이용한 선박 침로유지 실험 연구 \\ 임남균 $^{* \dagger} \cdot$ 트란반룽** \\ *, ** 목포해양대학교 해상운송시스템학부
}

\begin{abstract}
This research presents an analysis of algorithm for ship track-keeping along a given trajectory. The maneuver of a free running model ship guiding through a simple path are presented. In order to solve the above problem, a desired trajectory is usually determined by GPS points in a pre-fixed place then these points are set in a pre-programmed navigation so that the ship would be automatically tracked. Proportional-Derivative(PD) control which is useful for fast response controllers was used in this program as a course keeping system. A high accuracy GPS receiver was installed on the model ship that could provide positions frequently, the system will compare and give out the remaining distance and heading to the target way-point. The results of ship auto track-keeping experiment will be explained in order to illustrate the adjustment in controlling parameters. These results can be utilized as a preliminary step to carry out the experiment of ship collision avoidance system and automatic berthing in the future.
\end{abstract}

Key Words : Ship's track-keeping, PD control, Free running model, GPS, Ship manoeuvering

요 약 : 본 연구는 미리 지정된 항로를 따라 항해하기 위한 선박의 Track-keeping에 대한 기초 실험 연구 분석결과를 제시하였다. 항로상에 위치한 여러 가지 변침점을 설정하고, 해당 선박이 그 항로를 항해하도록 알고리즘을 구성, 모형선을 이용한 실험 결과를 보여주었다. 지정된 구 역에서 GPS로 변침점을 설정하고, 그 포인트를 Data화하여, 미리 프로그램된 알고리즘에 입력하면 해당 선박이 자동으로 항로를 항해하도록 설 계되었다. PD 제어를 이용하여 침로 유지 알고리즘을 구성하였고, 선박 자동 Track-keeping 결과는 모니터링 가능토록 하였고, 변수를 설정 변 경하도록 설계되었다. 제시된 알고리즘은 실험을 통하여 그 알고리즘의 효용성을 확인할 수 있었으며, 실선의 항해 자동화 및 충돌회피, 자동접 안 등의 다양한 분야에 응용될 수 있을 것으로 판단된다.

핵심용어 : 선박침로유지, $\mathrm{PD}$ 제어, 자유항주선, 지피에스, 선박조종

\section{Introduction}

Experiments for ship track-keeping algorithms have been carried out using simulators or small-scale ship model and their good results were proved. Källström(1999) suggested track autopilot predictor(TAP) system for high-speed craft and showed its satisfactory performance through his experimental procedures. Ship track-keeping using a tanker model was also carried out by Morawski(1998); in his research, two algorithms based on well-known methods were tested and the experimental results showed its efficiency for auto pilots system. Recently, Kim(2009) developed an autonomous navigation algorithm for small unmanned vehicle based on GPS. In his study, very small box-type vehicle was

† Corresponding author : namkyun.im@mmu.ac.kr, 061-240-7177 adopted as a model using proportional method(Kp) so that the results was not enough to be applicable to a ship type vehicle or other applicable study.

The function of ship track-keeping is one of the most common applications of automatic control theory and it can be used in various ways in ship maneuvering field.. In the crowded or constrained water area, the more precise ship track-keeping performance is, the more safety the ship can process. In this study, proportional-derivative(PD) controller was adopted as a tool to control the model ship on a given trajectory. The model ship are equipped with a very high precision GPS receiver and wireless radio communication system to identify its positions.

An experiment for automatic ship track-keeping was carried out at Namhang area(Mokpo port area) and the results have shown the good performance. It is believed that, 
these results can be utilized as a part of ship intelligent maneuvering experiments in the future such as ship automatic collision avoidance system, ship automatic berthing procedure, etc.

\section{The free running model ship installation}

The control experiments were carried out with a free running model ship of a tanker. The free running model ship consists of several parts system as follows

- Model ship

- Control system

- Operating system and data transition

- GPS receiver.

The scale ratio of the model is $1 / 100$ and its details can be referred to $\operatorname{Im}(2009)$. The particulars and overview of the are shown in Fig. 1 and Table 1.

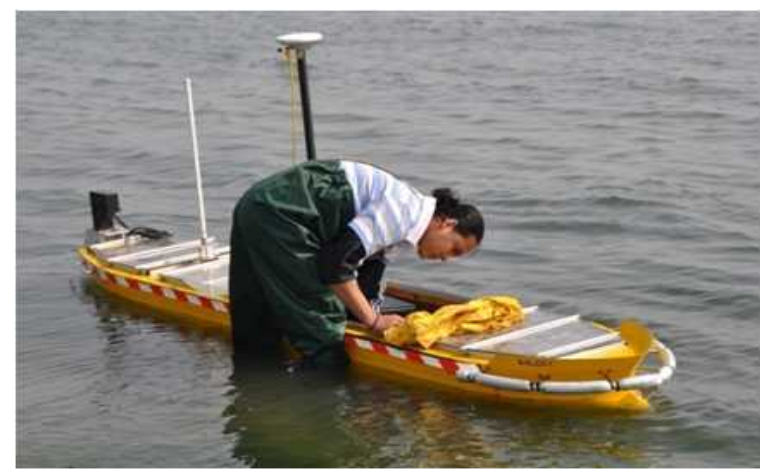

Fig. 1. The overview of model ship.

Table 1. Principal particulars of model ship

\begin{tabular}{|c|c|c|}
\hline Designation & Real Ship & Model \\
\hline Scale ratio & 1 & $1 / 100$ \\
\hline Type & Tanker & Tanker \\
\hline Froude number & 0.142 & 0.142 \\
\hline Design speed(m/s) & 7.9739 & 0.79739 \\
\hline Lpp $(\mathrm{m})$ & 320 & 3.2 \\
\hline B $(\mathrm{m})$ & 58 & 0.58 \\
\hline Depth $(\mathrm{m})$ & 30 & 0.3 \\
\hline Draft $(\mathrm{m})$ & 20 & 0.2 \\
\hline Displacement $\left(\mathrm{m}^{3}\right)$ & 312737.5 & 0.3127 \\
\hline
\end{tabular}

The control devices consist of access point, laptop, PMAC, servo driver and wireless control system, as described in Fig. 2.

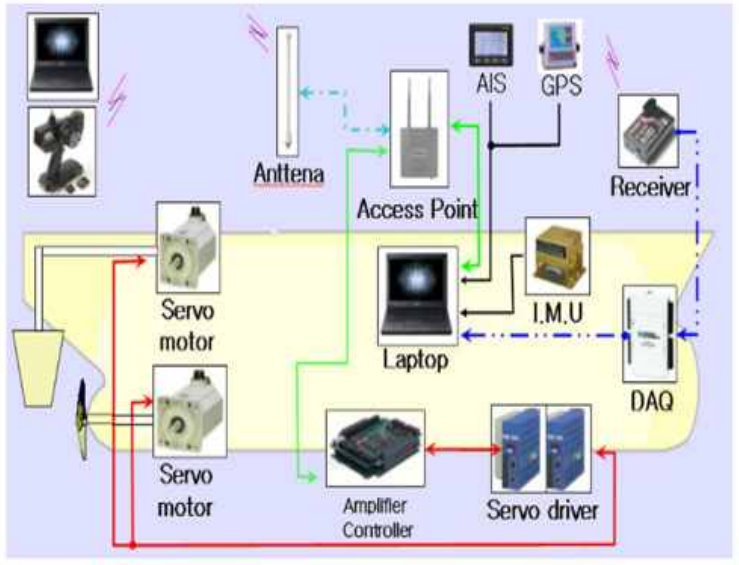

Fig. 2. Block diagram of model ship and control system

Operating system is operated by inner computer on board which is controlled from shore computer via wireless network communication. Fig. 3 shows the main screen of operating program in which three control modes are displayed. First control mode is local control where the model ship is controlled manually by adjusting RPM and rudder angle values. The second one is Auto tracking mode in which several maneuvering auto tests are available, such as zig-zag test, auto track-keeping etc.. The last one is remote control mode where the model ship can be controlled by a priority radio control receiver-transmitter in specified frequency to cope with emergency situation.

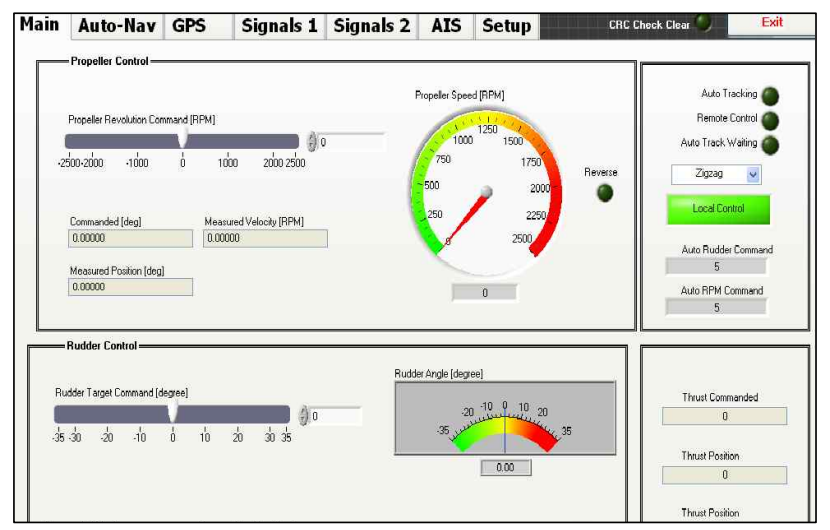

Fig. 3. Main screen of operating program.

Fig. 4 shows the auto-navigation controller screen where PD's gains, $K_{p}, K_{d,}$ can be adjusted, and points of designed track can also be input, parameters of target point such as heading, remaining distance and ship position are frequently updated 


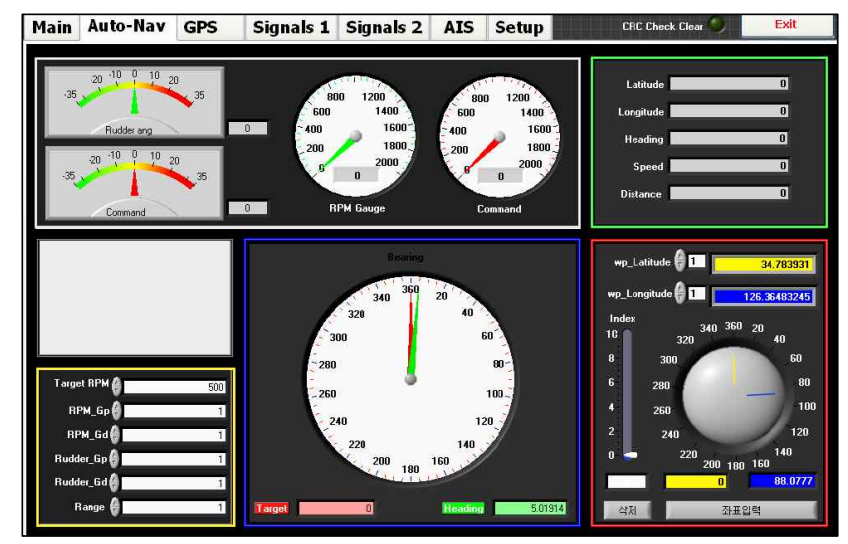

Fig. 4. Module program of the auto-navigation controller.

Whole system is equipped with high precision R5 Trimble GPS receiver and wireless radio communication device that can perform real time kinematics(RTK) positioning operation. The receiver records GPS data on an internal CompactFlash card and makes all data available through serial or USB ports. It is divided into two stations: Shore station and mobile station, the former gets the precision position, compares and then transmits the correction via radio transmitter to the mobile station which is installed at model ship. The GPS receiver system in shore base is shown in Fig. 5.

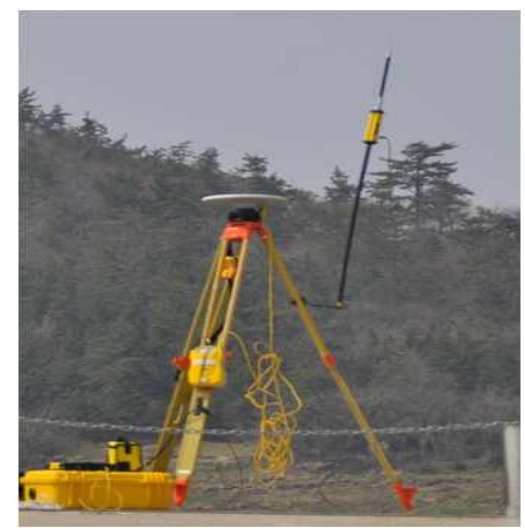

Fig. 5. Shore base GPS receiver.

\section{Ship track-keeping algorithm}

\subsection{PD controller introduction}

In this study, proportional derivative(PD) controller is used to maintain the model on its' tracks. Generally the PD controller have been known as an useful tool for fast response controller that does not need a steady-state error of 0 . The combination of proportional-part(P) which is fast in response and derivative-part(D) which is fast also, would make a very fast response to the control system. As in the case of Sperry's work(1922), PD controller designs were based on visual observation of the way as an experienced helmsman would steer the ship. He acknowledged that helmsman would anticipate ship motions before applying rudder corrections. But more importantly he postulated that they possessed the ability to judge angular velocity and yaw rate, thereby effecting derivative control. Indeed, it is worth noting that the ability of a human operator to estimate innately velocity is now widely accepted in human factor research. This paper also applies the previous researches and develops those result by carrying out experiment with free running model ship from Mokpo National Maritime University. Fig. 6 below shows the close-loop system.

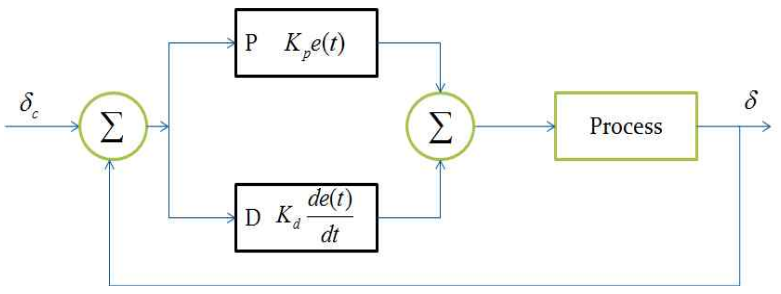

Fig. 6. Block diagram of the PD controller.

As mentioned above, PD controller algorithm involves two separate parameters, these values can be interpreted in terms of time: $\mathrm{P}$ depends on the present error and $\mathrm{D}$ is a prediction of future error. The weighted sum of these two actions is used to adjust the process via a control heading of the model ship through rudder's angle value. This procedure can be displayed briefly as following equation:

$$
\delta=K_{p} e(t)+K_{d} \frac{d e(t)}{d t}
$$

Where $K_{p}, K_{d}$ are proportional gain, derivative gain respectively and $e$ is the deviation between ship present heading $\left(\psi_{P}\right)$ and target heading $\left(\psi_{T}\right)$.

$$
e=\psi_{P}-\psi_{T}
$$

The proposed model ship track-keeping consists of a very high precision GPS receiver so that the ship position and other related information are regularly provided to the system. Fig. 7 shows the general flow of control system, which GPS signal provides the system with heading and distance to target point. The system compares these parameters with the previous data then calculates the output of rudder command angle. 
-35 to 35

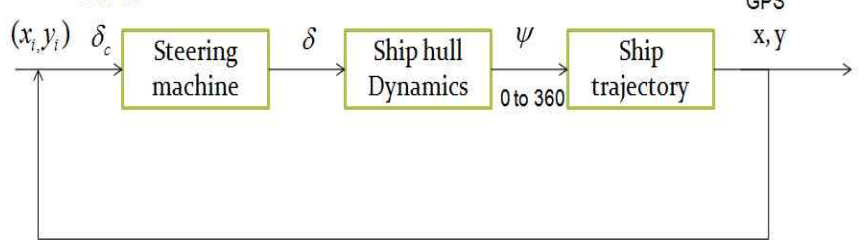

Fig. 7. Block diagram of the close-loop system.

\subsection{Ship track design}

In ship track-keeping, a desired trajectory is usually determined as series of straight lines connected by several fixed points. In this study, some points were selected randomly by GPS receiver, and it is necessary to convert these positions(latitude, longitude) into metric system for observation and comparison with the experimental results.

The Fig. 8 shows the coordinate system to convert ship positions.

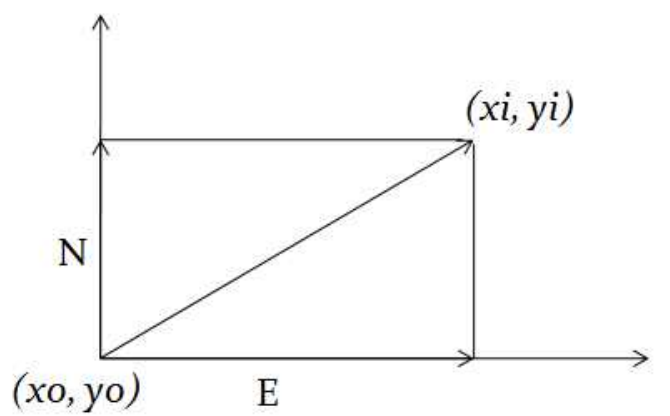

Fig. 8. Coordinate system for converting ship position.

As shown in Fig. 8, original point $\left(x_{0}, y_{0}\right)$ is firstly selected as starting position of the model ship, then the distances from origin to any point $\left(x_{i}, y_{i}\right)$ toward $\operatorname{North}(N)$ and $\operatorname{East}(E)$ are calculated by following equation:

$$
\begin{aligned}
& N=R_{m}\left(x_{i}-x_{o}\right) \\
& E=R_{p}\left(y_{i}-y_{o}\right)
\end{aligned}
$$

Where, $R_{m}$ and $R_{p}$ are radius of median and radius of parallel, respectively which can be determined as follows:

$$
\begin{gathered}
R_{m}=\frac{a\left(1-e_{w}^{2}\right)}{1-e_{w}^{2} \sin ^{2}\left(x_{i}\right)^{\frac{3}{2}}} \\
R_{p}=\frac{a \cos \left(x_{i}\right)}{1-e_{w}^{2} \sin ^{2}\left(x_{i}\right)^{\frac{1}{2}}}
\end{gathered}
$$


Table 2. Weather condition

\begin{tabular}{|c|c|c|}
\hline Time(2010 Aug. 09) & Wind course & Wind velocity $(\mathrm{m} / \mathrm{s})$ \\
\hline $15: 00$ & $\mathrm{SE}$ & 3.6 \\
\hline $16: 00$ & $\mathrm{SE}$ & 3.9 \\
\hline $17: 00$ & $\mathrm{SE}$ & 3.3 \\
\hline $18: 00$ & $\mathrm{SE}$ & 3.6 \\
\hline $19: 00$ & $\mathrm{SE}$ & 3.0 \\
\hline
\end{tabular}

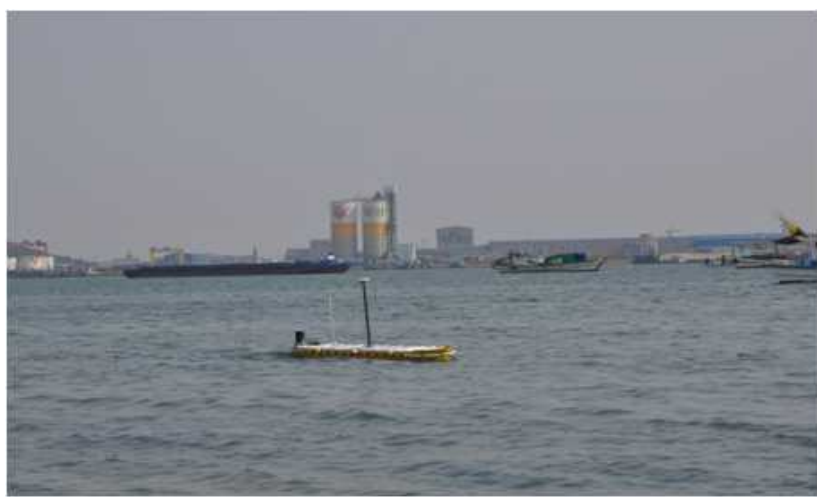

Fig. 11. Experimental scene.

The thin straight line in Fig. 12 is the designed track and the thick curved line is the ship trajectory. The designed track was made when there was no current, but while the experiment was carried out, due to the rapid tide, the model ship had to be stopped earlier to prevent its damage. This made the ship trajectory interrupted. However, as shown in Fig. 12, it can be seen that the model ship is intending to reach the final point at last. The deviation between the designed track and ship trajectory is significant because it depends on two factors, the most effective one is the influence of the surface wave, the other is the selected gain of proportion and derivative in the controller. Approximate off-track error is shown in Fig. 13 where the devidation is considerable. Maximum off-track error is about $2.8 \mathrm{Lp}$, it could be reduced when effect of wind, current is considered.

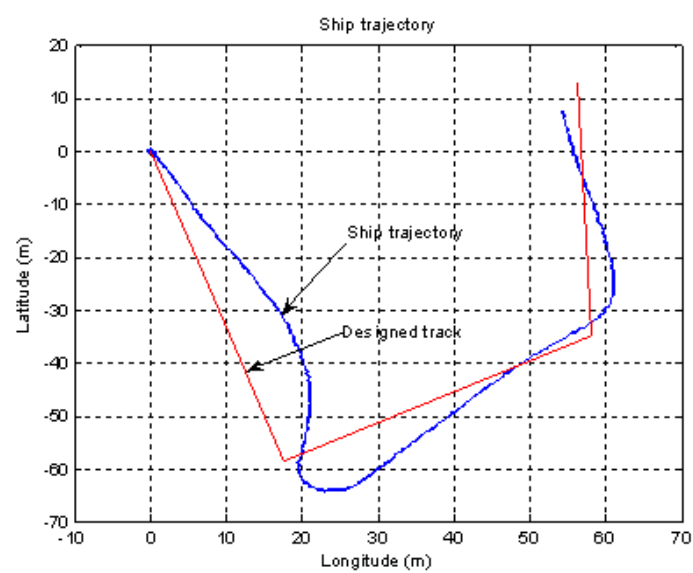

Fig. 12. Ship trajectory.

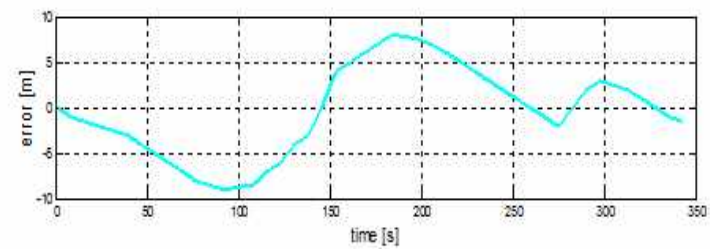

Fig. 13. Approximate off-track error.

Fig. 14 and Fig. 15 shows the time-history of all parameters recorded during experiment. Sub-plot 2 in Fig. 14 indicates the heading to target point and the ship present heading, despite of some error between designed track and ship, trajectory as mentioned above, the ship current heading is always followed with the target heading. It means that the used controller is proper and the experiment shows the good performance of ship course-keeping.
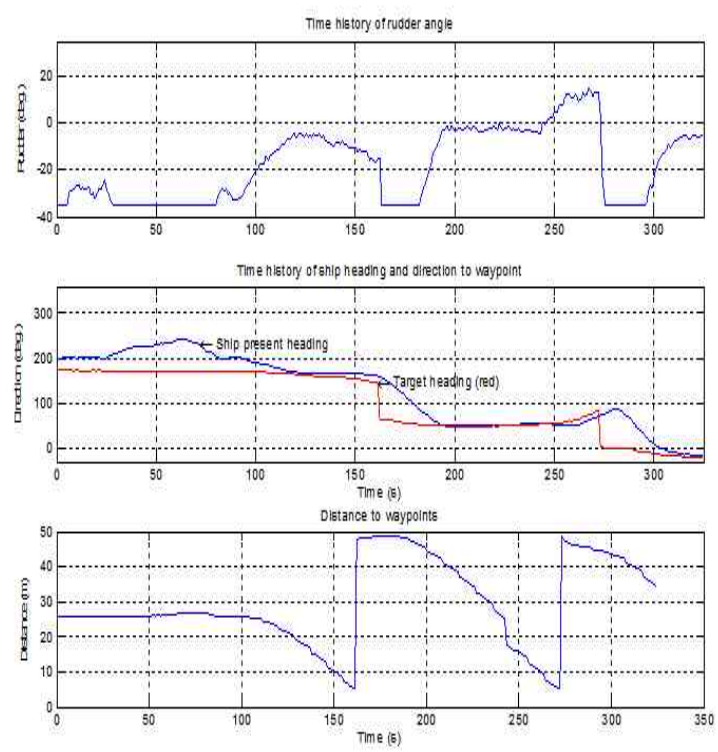

Fig. 14. Time-history of parameters: Used rudder angle, directions, distances.
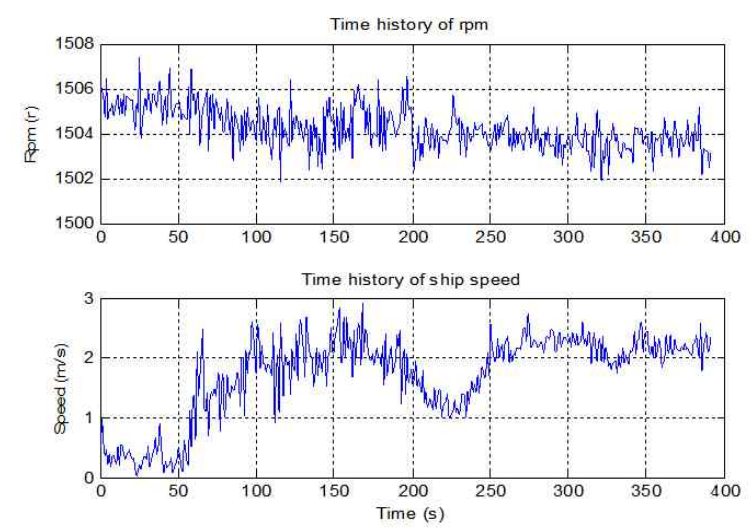

Fig. 15. Time-history of parameters : Model ship velocity. 


\section{Conclusion}

The conclusion of this study can be summarized as follows.

- Ship track design and its calculated method were briefly introduced.

- The main structure and the concept of free running model ship were mentioned.

- The PD algorithm for track-keeping. was designed as a controller.

- The track-keeping autopilot experiments using a free running model were examined.

- It was found that the experiment results satisfied the proposed controller design.

However, more experiments should be carried out to verify these proposal idea. The effect of external disturbances to the system also should be considered. In spite of these limitation, the experimental results in this study can be utilized as a step to carry out other intelligent maneuvering tests such as ship automatic collision avoidance system, berthing/unberthing system. This work will be considered in the future.

\section{References}

[1] Källström, C. G.(1999), "Autopilot and Track-keeping Algorithms for High-speed Craft”, Control Engineering Practice 8, pp. 185-190.

[2] Morawski, L.(1998), "Ship Track-keeping: Experiments with a Physical Tanker Model", Control Engineering Practice 6, pp. 763-769.

[3] Im, Namkyun(2009), "Ship Manoeuvring Performance Experiments Using a Free Running Model Ship", Journal of Navigation and Port Research, Korea, Vol. 33, No. 9, pp. 6031-608.

[4] Kim, Hyo-Il(2009), "Development of Autonomous Navigation Algorithm for Very Small Unmanned Surface Vehicle base on GPS", Journal of Navigation and Port Research, Korea, Vol. 33, No. 5, pp. 303-308.

[5] Sperry, E. A.(1922). Automatic steering. Transactions, Society of Naval Architects and Marine Engineers, pp. 61-63.

\footnotetext{
Received : 2011. 10. 07.

Revised : 2012. 03. 19. (1st)

2012. 04. 12. (2nd)
}

Accepted : 2012. 06. 25. 